\title{
The association between serum lipids and risk of premature mortality in Latin America: A systematic review of population- based prospective cohort studies
}

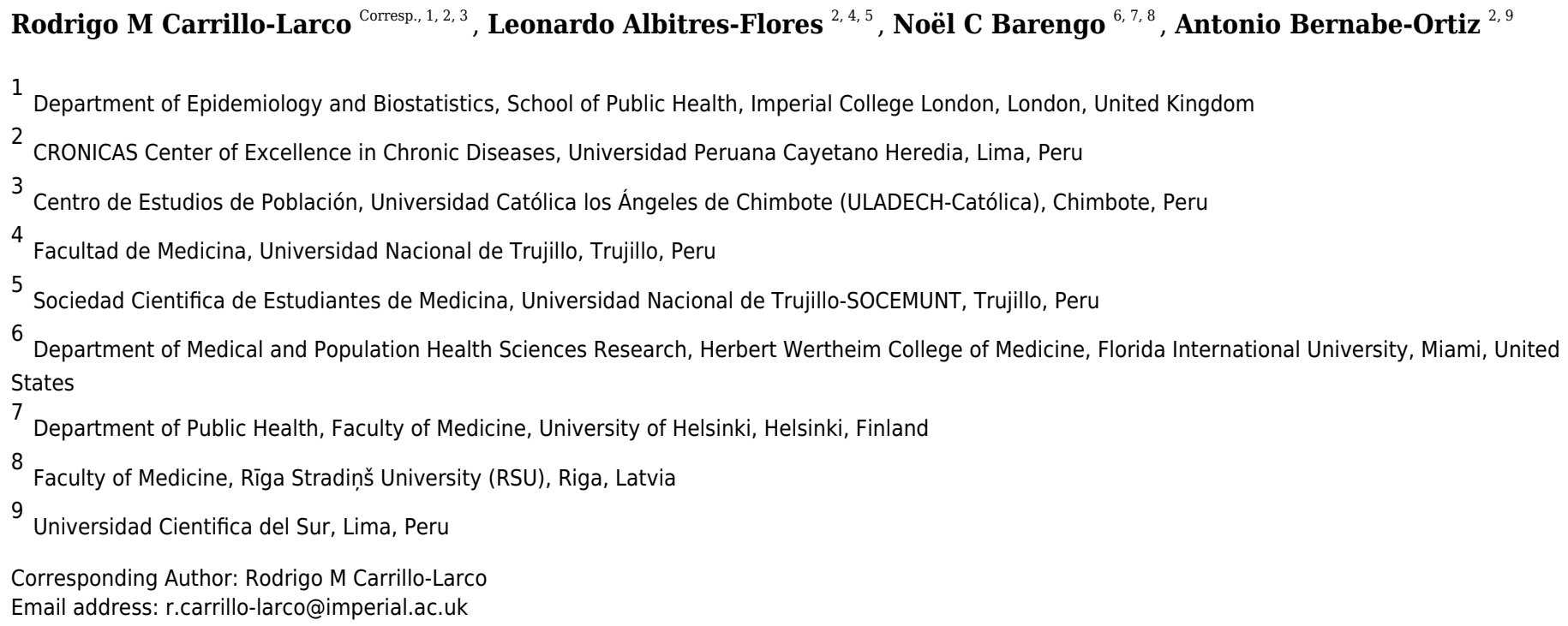

Objective: To synthetize the scientific evidence on the association between serum lipids and premature mortality in Latin America (LA). Methods: Five data bases were searched from inception without language restrictions: Embase, Medline, Global Health, Scopus and LILACS. Population-based studies following random sampling methods were identified. The exposure variable was lipid biomarkers (e.g., total, LDL- or HDL- cholesterol). The outcome was all-cause and cause-specific mortality. The risk of bias was assessed following the Newcastle-Ottawa criteria. Results were summarized qualitatively. Results: The initial search resulted in 264 abstracts, five $(N=27,903)$ were included for the synthesis. Three papers reported on the same study from Puerto Rico (baseline in 1965), one was from Brazil (1996) and one from Peru (2007). All reports analysed different exposure variables and used different risk estimates (relative risks, hazard ratios or odds ratios). None of the reviewed reports showed strong association between individual lipid biomarkers and allcause or cardiovascular mortality. Conclusion: The available evidence is outdated, inconsistently reported on several lipid biomarker definitions and used different methods to study the long-term mortality risk. These findings strongly support the need to better ascertain the mortality risk associated with lipid biomarkers in LA. 
1 The association between serum lipids and risk of premature mortality in Latin America: A 2 systematic review of population-based prospective cohort studies

3 [Lipid profile and mortality]

4

5 Rodrigo M Carrillo-Larco $1,2,3$

6 Leonardo Albitres-Flores ${ }^{2,4,5}$

7 Noël C Barengo ${ }^{6,7,8}$

8 Antonio Bernabe-Ortiz 2,9

1. Department of Epidemiology and Biostatistics, School of Public Health, Imperial College London, London, UK

2. CRONICAS Centre of Excellence in Chronic Diseases, Universidad Peruana Cayetano Heredia, Lima, Peru

3. Centro de Estudios de Población, Universidad Católica los Ángeles de Chimbote (ULADECHCatólica), Chimbote, Perú

4. Facultad de Medicina, Universidad Nacional de Trujillo, Trujillo, Peru

5. Sociedad Cientifica de Estudiantes de Medicina de la Universidad Nacional de TrujilloSOCEMUNT, Trujillo, Peru

6. Department of Medical and Population Health Sciences Research, Herbert Wertheim College of Medicine, Florida International University, Miami, FL, USA

7. Department of Public Health, Faculty of Medicine, University of Helsinki, Finland

8. Faculty of Medicine, Rīga Stradiňš University (RSU), Riga, Latvia

9. Universidad Científica del Sur, Lima, Peru

\section{Corresponding author}

Rodrigo M Carrillo-Larco, MD

Department of Epidemiology and Biostatistics

School of Public Health, Imperial College London, London W2 1PG, UK

E-mail: rcarrill@ic.ac.uk

Phone: +44 07578240395

Competing interests: The authors declare that they have no competing interests.

Funding: Strategic Award, Wellcome Trust-Imperial College Centre for Global Health Research (100693/Z/12/Z). Imperial College London Wellcome Trust Institutional Strategic Support Fund [Global Health Clinical Research Training Fellowship] (294834/Z/16/Z ISSF ICL). Rodrigo M Carrillo-Larco is supported by a Wellcome Trust International Training Fellowship (214185/Z/18/Z). 


\section{ABSTRACT}

Objective: To synthetize the scientific evidence on the association between serum lipids and premature 41 mortality in Latin America (LA).

42 Methods: Five data bases were searched from inception without language restrictions: Embase, Medline, 43 Global Health, Scopus and LILACS. Population-based studies following random sampling methods were 44 identified. The exposure variable was lipid biomarkers (e.g., total, LDL- or HDL- cholesterol). The outcome was all-cause and cause-specific mortality. The risk of bias was assessed following the Newcastle-Ottawa criteria. Results were summarized qualitatively.

47 Results: The initial search resulted in 264 abstracts, five $(N=27,903)$ were included for the synthesis. Three papers reported on the same study from Puerto Rico (baseline in 1965), one was from Brazil (1996) and one from Peru (2007). All reports analysed different exposure variables and used different risk estimates

50 (relative risks, hazard ratios or odds ratios). None of the reviewed reports showed strong association 51 between individual lipid biomarkers and all-cause or cardiovascular mortality.

52 Conclusion: The available evidence is outdated, inconsistently reported on several lipid biomarker 53 definitions and used different methods to study the long-term mortality risk. These findings strongly support 54 the need to better ascertain the mortality risk associated with lipid biomarkers in LA.

Keywords: Cholesterol; dyslipidaemias; survival; South America; Central America; the Caribbean 


\section{INTRODUCTION}

58 An unfavourable serum lipid profile such as increased total cholesterol or LDL-cholesterol is an important 59 determinant of cardiovascular diseases causing large negative health consequences in low- and middle-

60 income countries (LMICs).(GBD 2017 Risk Factor Collaborators 2018; Global Burden of Metabolic Risk Factors for Chronic Diseases Collaboration 2014) Understanding the long-term effects of lipids on health is relevant to support the current national and international guidelines which provide recommendations for their management to achieve good cardiovascular health.(Catapano et al. 2016; Grundy et al. 2018; NICE 2014) In addition, many risk scores for primary prevention of cardiovascular diseases include lipid measurements as one of their predictors. (Conroy RM et al. 2003; D'Agostino RB Sr et al. 2008; Goff DC Jr et al. 2014) (Conroy RM et al. 2003; D'Agostino RB Sr et al. 2008; Goff DC Jr et al. 2014) Despite of the relevance of serum lipids and use in clinical medicine, the epidemiological research is still limited in LMICs including Latin America (LA).(Ponte-Negretti et al. 2017)

Epidemiological studies have reported inconsistent findings about the association between lipids and premature cardiovascular mortality.(Di Angelantonio et al. 2009; Lewington et al. 2007) The Prospective Studies Collaboration reported a lower hazard of death due to ischaemic heart disease for each $1 \mathrm{mmol} / \mathrm{L}$ reduction of total cholesterol.(Lewington et al. 2007) However, the evidence of an association between serum lipids and cerebrovascular disease mortality was less consistent in their study.(Lewington et al. 2007) Furthermore, the Emerging Risk Factor Collaboration revealed a higher hazard of death due to coronary heart diseases for people with increased cholesterol and LDL-cholesterol levels and those with decreased HDL-cholesterol.(Di Angelantonio et al. 2009) Again, the evidence was less conclusive when the main outcome was ischaemic stroke mortality.(Di Angelantonio et al. 2009) Other prospective studies have reported that the association between total cholesterol and stroke mortality varies according to stroke sub-type.(Yi et al. 2018) Moreover, a study including people aged 60 years and above reported a reduced mortality between increased serum total cholesterol and all-cause mortality, most likely due to a high number of non-cardiovascular deaths;(Liang et al. 2017) similarly, LDL-cholesterol seems to have an negative correlation with mortality in people 60 years old and above.(Ravnskov et al. 2016) These inconsistent findings have not included populations in LA, where different distribution of cholesterol levels, health profiles and access to healthcare or pharmaceutical treatment,(Atun et al. 2015; Cotlear et al. 2015; 
85 Farzadfar et al. 2011) exist. Therefore, summarizing studies on the association between lipid biomarkers 86 and mortality in LA populations may complement international evidence, as well as provide valuable 87 information for the development of local guidelines for clinicians and health policy makers. The objective of 88 this study was to synthetize through a systematic review the current scientific evidence on the association 89 between serum lipids and premature mortality in LA.

90 


\section{METHODS}

92 Protocol

93 We conducted a systematic review of the literature following the PRISMA guidelines (supplementary 94 material pp. 02-04).(Liberati et al. 2009) The protocol was registered at PROSPERO (CRD42019120491).

95 Epidemiological studies in adults assessing the association between lipid biomarkers (e.g., total 96 cholesterol) and all-cause as well as cause-specific mortality in LA populations were aimed for. Although no specific comparator was sought, we aimed to study the mortality risk of impaired levels of lipid biomarkers in comparison with recommended levels or per unit change in $\mathrm{mg} / \mathrm{dL}$ or $\mathrm{mmol} / \mathrm{L}$.

\section{Study selection}

113 The search results were downloaded and compiled in EndNote, where duplicates were identified and 114 excluded. A second search for duplicates was conducted online with Rayyan.(Ouzzani et al. 2016)

115 Screening of titles and abstracts was performed by two independent reviewers (RMC-L, LA-F) following the 116

\section{Eligibility criteria}

We searched for observational prospective cohort studies without any language restrictions regardless of publication time. The study population comprised individuals from all LA countries. Studies addressing LA people in foreign countries or foreigners in LA countries were excluded. We aimed for population-based studies which had followed a random sampling technique to select the study population. Hospital-based studies, convenient samples or participants selected based on a diagnosis (e.g., patients with diabetes) or risk factor (e.g., obese individuals) were excluded. The exposure of interest was any lipid biomarker, including but not limited to total cholesterol, HDL-cholesterol, LDL-cholesterol or triglycerides.

\section{Information sources}

The search was conducted in five data bases: Embase, Global Health and Medline through Ovid, Scopus and LILACS. The search was conducted on December 215t, 2018. No additional sources of scientific information were considered. The search strategy used in these search engines is available under supplementary material pp. 05-07. selection criteria above detailed; discrepancies were solved by consensus between them. The full text of 
117 the selected reports was studied in detail by the same reviewers, also following the above explained criteria;

118 discrepancies were solved by consensus as well. The two stages of the selection process were conducted

119 with the online tool Rayyan.(Ouzzani et al. 2016)

120 When multiple reports were found for one study, the following algorithm was followed to select one

121 report for inclusion in qualitative synthesis: i) if they reported on different outcomes (e.g., all-cause and 122 cardiovascular mortality), then all the reports were included; and ii) the report which analysed the longer 123 follow-up time was included.

124

125

126

127

128

129

130

131

132

133

134

135

136

137

138

139

140

141

142

\section{Data collection}

With the final list of selected reports, information was extracted onto an Excel sheet developed by the authors before data collection started and was not modified afterwards; this form collected similar information as in Ravnskov et al.(Ravnskov et al. 2016) The extraction form included information about the study (authors, year of publication, country), about the study population (sample size, age and sex ratio at baseline, follow-up time), and about the distribution of lipid biomarkers including mean and/or prevalence according to data availability in each selected report. Moreover, to assess the mortality risk, risk estimates such as relative risks or hazard ratios were extracted according to what was reported in the original paper. Data extraction was conducted by one reviewer (RMC-L) and independently verified by another one (ABO); discrepancies were solved by consensus between them.

\section{Risk of bias in individual studies}

The Newcastle-Ottawa Scale was used to assess the risk of bias in the selected reports.(GA Wells et al.) The risk of bias assessment was conducted by one reviewer (LA-F) and independently verified by another one $(A B-O)$. If there were discrepancies, these were solved by consensus between these reviewers.

\section{Summary measures}

We conducted a qualitative synthesis, and where relevant the risk estimates as described in the original report were summarized. No quantitative synthesis such as a meta-analysis was possible to conduct because of the few retrieved reports, which also exhibited large heterogeneity in the lipid biomarkers assessed, outcomes, and statistical methods. 


\section{Ethical considerations}

144 This project was classified as non-human subject research. This is a systematic review of published and

145 open information where no human subjects participated. Approval from an IRB/ethics committee was not 146 necessary. 


\section{RESULTS}

\section{Study selection}

149 After duplicates were removed, 264 titles and abstracts were screened for eligibility, and 23 were further 150 studied in detail. Three manuscripts were excluded after applying the exclusion criteria:(Cruz-Vidal et al. 151 1983; Marafon et al. 2003; Sorlie \& Garcia-Palmieri 1990) two studies were excluded because a newer 152 report was available using the same data,(Cruz-Vidal et al. 1983; Marafon et al. 2003) and one because 153 the assessed outcome was the same as in another report of the same data.(Sorlie \& Garcia-Palmieri 1990) 154 Finally, five reports were included for qualitative synthesis $(N=27,903)$.(Crespo et al. 2002; Garcia-Palmieri 155 et al. 1981; Garcia-Palmieri et al. 1988; Lazo-Porras et al. 2016; Werle et al. 2011) Of the five selected 156 reports for qualitative synthesis, three were using the same project (Puerto Rico Heart Health 157 Program)(Crespo et al. 2002; Garcia-Palmieri et al. 1981; Garcia-Palmieri et al. 1988) and two were 158 independent studies in Peru(Lazo-Porras et al. 2016) and Brazil.(Werle et al. 2011) Figure 1 presents the number of studies at each stage of the selection process and the reasons for exclusion.

160

161

162

163

164

165

166

167

168

169

170

171

172

173

\section{Study characteristics}

Three reports collected baseline data in 1965,(Crespo et al. 2002; Garcia-Palmieri et al. 1981; GarciaPalmieri et al. 1988) one in 1996(Werle et al. 2011) and one in 2007.(Lazo-Porras et al. 2016) Four reports included middle-aged adults,(Crespo et al. 2002; Garcia-Palmieri et al. 1981; Garcia-Palmieri et al. 1988; Lazo-Porras et al. 2016) while one studied the elderly (mean age $=83.6$ years).(Werle et al. 2011) Three reports included only men,(Crespo et al. 2002; Garcia-Palmieri et al. 1981; Garcia-Palmieri et al. 1988) in one report men accounted for almost half of the study population (47.2\%),(Lazo-Porras et al. 2016) and in other report the proportion of men was smaller (36.4\%).(Werle et al. 2011) The follow-up time varied from 5 to 12 years.(Crespo et al. 2002; Garcia-Palmieri et al. 1981; Garcia-Palmieri et al. 1988; Lazo-Porras et al. 2016; Werle et al. 2011) The outcome of the three reports from Puerto Rico were all-cause mortality,(Crespo et al. 2002) cardiovascular disease mortality,(Garcia-Palmieri et al. 1988) and cancer mortality.(Garcia-Palmieri et al. 1981) Werle and colleagues studied cardiovascular disease mortality,(Werle et al. 2011) whereas Lazo-Porras et al. assessed all-cause and cardiovascular mortality.(Lazo-Porras et al. 2016) Details about the study characteristics are shown in Table 1. 
174

175

176

177

178

179

180

181

182

183

184

185

186

187

188

189

190

191

192

193

194

195

196

197

198

199

\section{Lipid biomarkers at baseline}

Table 2 shows the means and prevalence estimates for the studied lipid biomarkers across the reports. The selected reports used different classifications to present prevalence estimates. For example, LazoPorras et al.(Lazo-Porras et al. 2016) reported the prevalence of low HDL-cholesterol (56.5\%), isolated low HDL-cholesterol (36.5\%), high non-HDL-cholesterol (91.6\%), low HDL-cholesterol with triglycerides $\geq 200$ $\mathrm{mg} / \mathrm{dL}$ (15.0\%), and low HDL-cholesterol with LDL-cholesterol >160 mg/dL (2.0\%). Crespo and colleagues showed the prevalence of total cholesterol $<200 \mathrm{mg} / \mathrm{dL}$ (50.9\%), $200-239 \mathrm{mg} / \mathrm{dL}(33.2 \%)$ and $\geq 240 \mathrm{mg} / \mathrm{dL}$ (15.9\%).(Crespo et al. 2002)

Other studies reported mean values. For example, Werle et al.(Werle et al. 2011) showed that the mean total cholesterol was 211.6 (SD: 47.4$) \mathrm{mg} / \mathrm{dL}$, HDL-cholesterol had a mean of 45.5 (SD: 12.6) mg/dL, the mean LDL-cholesterol was 139.1 (SD: 42.5) $\mathrm{mg} / \mathrm{dL}$, and the mean for triglycerides was 137.2 (SD: 65.6) $\mathrm{mg} / \mathrm{dL}$. Werle et al. also reported on ApoA-I and ApoB-100, with means of 165.4 (SD: 33.7) mg/dL and 87.5 (SD: 21.0) $\mathrm{mg} / \mathrm{dL}$, respectively.(Werle et al. 2011)

\section{Mortality risk}

Table 3 (supplementary material p. 08) summarizes the risk estimates as provided by each report. All selected reports analysed different exposure variables not allowing to conduct a meta-analysis. In addition, the reports used different risk estimates including relative risks $(R R)$, hazard ratios $(H R)$ and odds ratios (OR).

Lazo-Porras et al.(Lazo-Porras et al. 2016) studied all-cause mortality based on a composite threelevel exposure variable: normal HDL-cholesterol vs isolated low HDL-cholesterol [HDL-c $<40 \mathrm{mg} / \mathrm{dL}$ in men and $<50 \mathrm{mg} / \mathrm{dL}$ in women without hypertriglyceridemia and $\mathrm{LDL}<160 \mathrm{mg} / \mathrm{dL}$ ] and non-isolated low HDLcholesterol [HDL-c $<40 \mathrm{mg} / \mathrm{dL}$ in men and $<50 \mathrm{mg} / \mathrm{dL}$ in women accompanied by hypertriglyceridemia and $L D L \geq 160 \mathrm{mg} / \mathrm{dL}$ ]; the first level was the reference category whereas the second and third exhibited a RR of 1.11 (95\% Cl: 0.49-2.51) and 0.82 (95\% Cl: 0.21-3.15), respectively.(Lazo-Porras et al. 2016) Crespo and colleagues also studied all-cause mortality in a cohort of men, showing $3 \%$ higher mortality risk in people with high total cholesterol in comparison to their peers with total cholesterol in the normal range; in 
200

201

202

203

204

205

206

207

208

209

210

211

212

213

214

215

216

217

218

219

220

221

222

223

224

addition, there was not higher risk when the latter group was compared with people with borderline high total cholesterol.(Crespo et al. 2002)

3

$$
\text { Werle and colleagues studied cardiovascular mortality associated with one-unit change }(\mathrm{mg} / \mathrm{dL}) \text { in }
$$
LDL-cholesterol (HR=1.00, 95\% Cl: 0.99-1.0.1), HDL-cholesterol (HR=1.01, 95\% Cl: 0.97-1.05), and ApoA (HR=0.99, 95\% Cl: 0.98-1.01).(Werle et al. 2011) Garcia-Palmieri's team reported on cardiovascular mortality too, though the magnitude of the effect was very small. (Garcia-Palmieri et al. 1988)

Garcia-Palmieri et al. used cancer mortality as main outcome reporting the OR for one-unit change $(\mathrm{mg} / \mathrm{dL})$ in total cholesterol by urban/rural location and age group. For example, in rural men aged 45-54 years, the OR was $0.54(p<0.05)$ for each $\mathrm{mg} / \mathrm{dL}$ increase in total cholesterol.(Garcia-Palmieri et al. 1981)

\section{Risk of bias}

Table 4 presents the summary of the risk of bias assessment, details in supplementary material p. 09. LazoPorras and colleagues(Lazo-Porras et al. 2016) authored the work with the least risk of bias, whereas both reports by Garcia-Palmieri et al.(Garcia-Palmieri et al. 1981; Garcia-Palmieri et al. 1988) showed the highest risk of bias mostly due to the comparability criteria.

\section{A narrative experience}

Lazo-Porras and colleagues studied the residual dyslipidaemic profile and its impact on mortality. Interestingly, they analysed a cohort of rural dwellers, urban people and rural-to-urban migrants (LazoPorras et al. 2016). These populations have unique features and these results could still be of interest to other LMICs where internal migration and urbanization is underway. However, one could argue on the pragmatic need, implications and applicability of these results in health policy or clinical practice.

Werle et al. reported on elderly individuals with relatively strong risk estimates (Werle et al. 2011). As aging is an ongoing process in LA and LMICs, these results and their implications among the oldest old could inform future studies in these populations. Nonetheless, this endeavour could not provide further arguments to advance the inconsistent findings among elderly populations, as signalled in the introduction. 
225 Garcia-Palmieri et al. and Crespo et al. analysed a cohort of men starting in 1965, and studied all-cause,

226 cardiovascular disease and cancer mortality (Crespo et al. 2002; Garcia-Palmieri et al. 1981; Garcia-

227 Palmieri et al. 1988). This is the largest cohort herein summarized where outcomes were comprehensively

228 adjudicated; however, because only men were included, these estimates could not successfully inform

229 clinical practice or public health for the whole population. Although these authors analysed cardiovascular

230 mortality, and so did Lazo-Porra's and Werle's team (Lazo-Porras et al. 2016; Werle et al. 2011), they did

231 not look at specific cardiovascular events, e.g., coronary heart disease, ischaemic stroke or haemorrhagic

232 stroke. Therefore, these reports could not provide additional evidence to elucidate the inconclusive

233 knowledge signalled in the introduction.

234 Overall, total cholesterol was the exposure mostly studied, except for Werle's and Lazo-Porras's work, 235 which included LDL-cholesterol and residual dyslipidaemic profile, respectively (Lazo-Porras et al. 2016;

236 Werle et al. 2011). The effect of total cholesterol on health outcomes such as mortality, could vary 237 depending on its composition, i.e., whether LDL-cholesterol levels are high. Conversely, LDL-cholesterol is 238 a well-stablished cardiovascular risk factor for which successful pharmacological treatment is available 239 (e.g., statins). Unfortunately, prospective evidence on the effect of LDL-cholesterol is still scarce in LA, 240 though much needed to inform clinical practice as well as recourse and treatment allocation. 


\section{DISCUSSION}

\section{Summary of evidence}

244 This systematic review of the literature in LA did not reveal scientific evidence on an association between 245 unfavourable serum lipid biomarkers and premature mortality in the general population. Furthermore, the 246 definitions used to categorize lipid biomarkers were inconsistent across reports. In addition, only one study 247 was conducted within the last ten years. Overall, our findings call to either conduct new cohort studies or 248 use available ones to systematically estimate the mortality risk associated with lipid profiles, using 249 consistent metrics and clinically relevant definitions. Thus, there is a need to study the long-term effects of 250 lipid profiles as this will provide evidence to inform local clinical practice, health policy and priority setting 251 for LA.

\section{Limitations of the review}

253 Even though we conducted a comprehensive literature search, including a LA-based search engine 254 (LILACS), we did not systematically search grey literature such as conference abstracts. We argue that, even if these sources had provided additional references, these would contain probably limited information.

Although some of the selected studies reported on relevant lipid biomarkers such as LDLcholesterol, they failed to analyse clinically relevant definitions. For example, Lazo-Porras and colleagues reported on several combinations of lipid metrics (e.g., low HDL-cholesterol and triglycerides $\geq 200 \mathrm{mg} / \mathrm{dL}$ ), but did not report on high LDL-cholesterol, which happens to be the lipid mainly targeted by pharmacological treatment for cardiovascular prevention.(Collins et al. 2016; Grundy et al. 2018; Yusuf et al. 2016)

261

262

263

264

265

266

267

\section{Results in context}

Previous large individual-level meta-analysis have assessed mortality risk associated with one unit change in lipids.(Di Angelantonio et al. 2009; Lewington et al. 2007) In this systematic review, the most recent study addressing this exposure was the work by Werle et al., whom reported that there was no strong evidence of higher risk.(Werle et al. 2011) Noteworthy, the study population in Werle's work had a mean age of 83 years.(Werle et al. 2011) Therefore, this finding is consistent with previous reports where the magnitude of the risk estimates would also decrease with age.(Lewington et al. 2007) Other recent systematic review 
268

269

270

271

272

273

274

275

276

277

278

279

280

281

282

283

284

285

286

287

288

289

290

291

292

293

294

studying people aged 60 years and above, also reported an inverse association between LDL-cholesterol and all-cause mortality.(Ravnskov et al. 2016) Despite this evidence, the use of statins in elderly still seems to reduce cardiovascular mortality.(Cholesterol Treatment Trialists' Collaboration 2019) Evidence in LA regarding young adults, middle-aged adults and elderly, is still limited to draw conclusions and formulate strong recommendations. For the time being, international guidelines should be followed along with clinical reasoning and shared decision making.

The INTERHEART, a case-control global endeavour studying myocardial infarction, reported that the association between this cardiovascular outcome and total cholesterol as well as non-HDL cholesterol was small in LA, in comparison to other world regions.(McQueen et al. 2008) Although this is a large and relevant scientific contribution, the results have the limitations of any case-control study. In addition, this was conducted almost ten years ago. Their findings deserve further verification with a stronger study design and more recent observations, to provide robust evidence that can be introduced in clinical and public health practice and that can account for the current trends in cardio-metabolic risk factors.

\section{Relevance for LA}

Strong scientific evidence is needed to develop successful policies, inform resources allocation, and advance clinical practice. Regarding lipid biomarkers and its associated mortality risk, much research is needed. A proposed call to action for LA is presented in Figure 2.

Despite limited scientific research in the field of lipid biomarkers in LA in general, there is a growing interest about this health profile in the clinical and public health communities of LA.(Ponte-Negretti et al. 2017) This interest has led to the development of local guidelines on management of hyperlipidaemias in some countries such as Mexico(Secretaria de Salud 2013) and Colombia(Sistema General de Seguridad Social en Salud - Colombia. 2014)(Sistema General de Seguridad Social en Salud - Colombia. 2014) among others. (Caja Costarricense de Seguridad Social. 2004; Sociedad Argentina de Cardiologia. 2018; Sociedad Uruguaya de Aterosclerosis.) (Caja Costarricense de Seguridad Social. 2004; Sociedad Argentina de Cardiologia. 2018; Sociedad Uruguaya de Aterosclerosis.) Analysing whether these local guidelines are in accordance with international recommendations or current scientific evidence is beyond the scope of this work, but definitely merits a close inspection.

Peer) reviewing PDF | (2019:06:38890:2:0:NEW 30 Aug 2019) 
To the best of our knowledge, no relevant international organization has set goals, targets or health

296

297

298

299

300

301

302

303

304

305

306

307

308

309

310

311

312

313

314

315

316

317

318

319

320

321

322

and research policies for the management and control of lipid biomarkers or dyslipidaemias in LA. Although a group of practitioners and researchers of LA has published a regional consensus highlighting key features of lipid profiles in LA,(Ponte-Negretti et al. 2017) further scientific evidence is needed for this momentum to foster research, policy and clinical practice. In addition to a consensus, additional pragmatic steps are needed.(Ponte-Negretti et al. 2017) For example, we recommend that this group(Ponte-Negretti et al. 2017) or other relevant professional or governmental body, issues a list of basic metrics that should be included and reported in any research studying lipid biomarkers in LA. These measures may allow to conduct metaanalysis and to estimate other population health metrics benefiting of consistent and comparable lipidrelated metrics throughout LA.

Most of the risk estimates used in the studies was total cholesterol. This lipid biomarker, although relevant and inexpensive, does not allow to identify whether a reduction of LDL-cholesterol or an increase of HDL-cholesterol is needed. A key determinant of lipid fraction is diet. Certain foods will increase LDLcholesterol whilst others will improve HDL-cholesterol and viceversa.(Forouhi et al. 2018; Schwingshackl et al. 2018) Because LA shows great variability in diet patterns between and within countries, this could define higher/lower levels of different lipid fractions. Future studies should try to ascertain lipid fractions in addition to total cholesterol.

Other determinants of lipid profiles are weight status and physical activity, whereby obesity increases LDL-cholesterol and decreases HDL-cholesterol whilst physical activity reduces LDL-cholesterol. Overweight and obesity have dramatically increased across LA in the last decades.(NCD Risk Factor Collaboration (NCD-RisC) 2017) Also, global analysis reported that women in LA have one of the largest prevalence estimates of physical inactivity.(Guthold et al. 2018) Although these risk factors need to be addressed on their own, these alarming trends also call to improve the study of lipid biomarkers in LA at the general population level. In this line, government and international agencies could potentiate national surveys to also collect lipid biomarkers such as in Mexico,(Aguilar-Salinas et al. 2010) Ecuador(Freire WB. et al. 2014)(Freire WB. et al. 2014) and Chile.(Margozzini \& Passi 2018) If in the next years these could be linked to death registries so that individual risks could be estimated, a major step forward in the study of lipid biomarkers would be achieved. 


\section{Conclusions}

324 To date, it is not possible to ascertain the association between lipid biomarkers and mortality risk in LA. The

325 available evidence is outdated, and the definitions of lipid biomarkers are inconsistent. In addition, different

326 methods were used to measure the long-term mortality risk in LA populations. These findings strongly

327 suggest conducting larger studies within the LA population to get valuable risk estimates of the associations

328 between serum lipids and premature mortality.

329 


\section{TABLES}

331 Table 1

332 Table2

333 Table3

334 Table 4

335 FIGURES

336 Figure 1. Flow-chart of the selection process.

337

338 Figure 2. Call to action for Latin America in research and policy. 
339

340

341

342

343

344

345

346

347

348

349

350

351

352

353

354

355

356

357

358

359

360

361

362

363

364

365

366

\section{REFERENCES}

Aguilar-Salinas CA, Gómez-Pérez FJ, Rull J, Villalpando S, Barquera S, and Rojas R. 2010. Prevalence of dyslipidemias in the Mexican National Health and Nutrition Survey 2006. Salud Pública de México 52:S44-S53.

Atun R, de Andrade LO, Almeida G, Cotlear D, Dmytraczenko T, Frenz P, Garcia P, Gomez-Dantes O, Knaul FM, Muntaner C, de Paula JB, Rigoli F, Serrate PC, and Wagstaff A. 2015. Health-system reform and universal health coverage in Latin America. Lancet 385:1230-1247.

Caja Costarricense de Seguridad Social. 2004. Guias para la deteccion, el diagnostico y el tratamiento de las dislipidemias para el primer nivel de atencion. URL: http://www.binasss.sa.cr/dislipidemias.pdf.

Catapano AL, Graham I, De Backer G, Wiklund O, Chapman MJ, Drexel H, Hoes AW, Jennings CS, Landmesser U, Pedersen TR, Reiner Z, Riccardi G, Taskinen MR, Tokgozoglu L, Verschuren WMM, Vlachopoulos C, Wood DA, Zamorano JL, and Cooney MT. 2016. 2016 ESC/EAS Guidelines for the Management of Dyslipidaemias. Eur Heart J 37:2999-3058.

Cholesterol Treatment Trialists' Collaboration. 2019. Efficacy and safety of statin therapy in older people: a meta-analysis of individual participant data from 28 randomised controlled trials. Lancet 393:407415.

Collins R, Reith C, Emberson J, Armitage J, Baigent C, Blackwell L, Blumenthal R, Danesh J, Smith GD, DeMets D, Evans S, Law M, MacMahon S, Martin S, Neal B, Poulter N, Preiss D, Ridker P, Roberts I, Rodgers A, Sandercock P, Schulz K, Sever P, Simes J, Smeeth L, Wald N, Yusuf S, and Peto R. 2016. Interpretation of the evidence for the efficacy and safety of statin therapy. Lancet 388:25322561.

Conroy RM, Pyörälä K, Fitzgerald AP, Sans S, Menotti A, De Backer G, De Bacquer D, Ducimetière P, Jousilahti P, Keil U, Njølstad I, Oganov RG, Thomsen T, Tunstall-Pedoe H, Tverdal A, Wedel H, Whincup P, Wilhelmsen L, Graham IM, and SCORE project group. 2003. Estimation of ten-year risk of fatal cardiovascular disease in Europe: the SCORE project. Eur Heart J 24:987-1003.

Cotlear D, Gomez-Dantes O, Knaul F, Atun R, Barreto IC, Cetrangolo O, Cueto M, Francke P, Frenz P, Guerrero R, Lozano R, Marten R, and Saenz R. 2015. Overcoming social segregation in health care in Latin America. Lancet 385:1248-1259.

Peer) reviewing PDF | (2019:06:38890:2:0:NEW 30 Aug 2019) 
367 Crespo CJ, Palmieri MR, Perdomo RP, McGee DL, Smit E, Sempos CT, Lee IM, and Sorlie PD. 2002. The 368 relationship of physical activity and body weight with all-cause mortality: results from the Puerto Rico Heart Health Program. Ann Epidemiol 12:543-552.

Cruz-Vidal M, Garcia-Palmieri MR, Costas R, Jr., Sorlie PD, and Havlik RJ. 1983. Abnormal blood glucose and coronary heart disease: the Puerto Rico Heart Health Program. Diabetes care 6:556-561.

D'Agostino RB Sr, Vasan RS, Pencina MJ, Wolf PA, Cobain M, Massaro JM, and WB. K. 2008. General cardiovascular risk profile for use in primary care: the Framingham Heart Study. . Circulation 117:743-753.

Di Angelantonio E, Sarwar N, Perry P, Kaptoge S, Ray KK, Thompson A, Wood AM, Lewington S, Sattar risk of vascular disease. JAMA 302:1993-2000.

Farzadfar F, Finucane MM, Danaei G, Pelizzari PM, Cowan MJ, Paciorek CJ, Singh GM, Lin JK, Stevens GA, Riley LM, and Ezzati M. 2011. National, regional, and global trends in serum total cholesterol since 1980: systematic analysis of health examination surveys and epidemiological studies with 321 country-years and 3.0 million participants. Lancet 377:578-586.

Forouhi NG, Krauss RM, Taubes G, and Willett W. 2018. Dietary fat and cardiometabolic health: evidence, controversies, and consensus for guidance. Bmj 361:k2139.

Freire WB., Ramírez-Luzuriaga MJ., Belmont P., Mendieta MJ., Silva-Jaramillo MK., Romero N., Sáenz K., Piñeiros P., Gómez LF., and R. M. 2014. Tomo I: Encuesta Nacional de Salud y Nutrición de la población ecuatoriana de cero a 59 años. ENSANUT-ECU 2012. Ministerio de Salud Pública/Instituto Nacional de Estadísticas y Censos. Quito-Ecuador. URL: https://biblio.flacsoandes.edu.ec/catalog/resGet.php?resld=55040.

GA Wells, B Shea, D O'Connell, J Peterson, V Welch, M Losos, and P Tugwell. The Newcastle-Ottawa Scale (NOS) for assessing the quality of nonrandomised studies in meta-analyses. URL: http://www.ohri.ca/programs/clinical epidemiology/oxford.asp.

Garcia-Palmieri MR, Sorlie PD, Costas R, Jr., and Havlik RJ. 1981. An apparent inverse relationship between serum cholesterol and cancer mortality in Puerto Rico. Am J Epidemiol 114:29-40. 
394 Garcia-Palmieri MR, Sorlie PD, Havlik RJ, Costas R, Jr., and Cruz-Vidal M. 1988. Urban-rural differences

395

396

397

398

399

400

401

402

403

404

405

406

407

408

409

410

411

412

413

414

415

416

417

418

419

420

421 in 12 year coronary heart disease mortality: the Puerto Rico Heart Health Program. J Clin Epidemiol 41:285-292.

GBD 2017 Risk Factor Collaborators. 2018. Global, regional, and national comparative risk assessment of 84 behavioural, environmental and occupational, and metabolic risks or clusters of risks for 195 countries and territories, 1990-2017: a systematic analysis for the Global Burden of Disease Study 2017. Lancet 392:1923-1994.

Global Burden of Metabolic Risk Factors for Chronic Diseases Collaboration. 2014. Cardiovascular disease, chronic kidney disease, and diabetes mortality burden of cardiometabolic risk factors from 1980 to 2010: a comparative risk assessment. Lancet Diabetes Endocrinol 2:634-647.

Goff DC Jr, Lloyd-Jones DM, Bennett G, Coady S, D'Agostino RB, Gibbons R, Greenland P, Lackland DT, Levy D, O'Donnell CJ, Robinson JG, Schwartz JS, Shero ST, Smith SC Jr, Sorlie P, Stone NJ, Wilson PW, Jordan HS, Nevo L, Wnek J, Anderson JL, Halperin JL, Albert NM, Bozkurt B, Brindis RG, Curtis LH, DeMets D, Hochman JS, Kovacs RJ, Ohman EM, Pressler SJ, Sellke FW, Shen WK, Smith SC Jr, Tomaselli GF, and American College of Cardiology/American Heart Association Task Force on Practice Guidelines. 2014. 2013 ACC/AHA guideline on the assessment of cardiovascular risk: a report of the American College of Cardiology/American Heart Association Task Force on Practice Guidelines. Circulation 129:S49-73.

Grundy SM, Stone NJ, Bailey AL, Beam C, Birtcher KK, Blumenthal RS, Braun LT, de Ferranti S, FaiellaTommasino J, Forman DE, Goldberg R, Heidenreich PA, Hlatky MA, Jones DW, Lloyd-Jones D, Lopez-Pajares N, Ndumele CE, Orringer CE, Peralta CA, Saseen JJ, Smith SC, Jr., Sperling L, $\begin{array}{llllll}\text { Virani } & \text { SS, } & \text { and } & \text { Yeboah } & \text { J. } & 2018 .\end{array}$ AHA/ACC/AACVPR/AAPA/ABC/ACPM/ADA/AGS/APhA/ASPC/NLA/PCNA Guideline on the Management of Blood Cholesterol: A Report of the American College of Cardiology/American Heart Association Task Force on Clinical Practice Guidelines. J Am Coll Cardiol.

Guthold R, Stevens GA, Riley LM, and Bull FC. 2018. Worldwide trends in insufficient physical activity from 2001 to 2016: a pooled analysis of 358 population-based surveys with 1.9 million participants. Lancet Glob Health 6:e1077-e1086. 
422

423

424

425

426

427

428

Lazo-Porras M, Bernabe-Ortiz A, Malaga G, Gilman RH, Acuna-Villaorduna A, Cardenas-Montero D, Smeeth L, and Miranda JJ. 2016. Low HDL cholesterol as a cardiovascular risk factor in rural, urban, and rural-urban migrants: PERU MIGRANT cohort study. Atherosclerosis 246:36-43.

Lewington S, Whitlock G, Clarke R, Sherliker P, Emberson J, Halsey J, Qizilbash N, Peto R, and Collins R. 2007. Blood cholesterol and vascular mortality by age, sex, and blood pressure: a meta-analysis of individual data from 61 prospective studies with 55,000 vascular deaths. Lancet 370:1829-1839.

Liang Y, Vetrano DL, and Qiu C. 2017. Serum total cholesterol and risk of cardiovascular and noncardiovascular mortality in old age: a population-based study. BMC Geriatr 17:294.

Liberati A, Altman DG, Tetzlaff J, Mulrow C, Gotzsche PC, loannidis JP, Clarke M, Devereaux PJ, Kleijnen J, and Moher D. 2009. The PRISMA statement for reporting systematic reviews and meta-analyses of studies that evaluate health care interventions: explanation and elaboration. PLoS Med 6:e1000100.

Marafon LP, da Cruz IB, Schwanke CH, and Moriguchi EH. 2003. [Cardiovascular mortality predictors in the oldest old]. Cad Saude Publica 19:799-807.

Margozzini P, and Passi Á. 2018. Encuesta Nacional de Salud, ENS 2016-2017: un aporte a la planificación sanitaria y políticas públicas en Chile. 2018 43:5.

McQueen MJ, Hawken S, Wang X, Ounpuu S, Sniderman A, Probstfield J, Steyn K, Sanderson JE, Hasani M, Volkova E, Kazmi K, and Yusuf S. 2008. Lipids, lipoproteins, and apolipoproteins as risk markers of myocardial infarction in 52 countries (the INTERHEART study): a case-control study. Lancet 372:224-233.

NCD Risk Factor Collaboration (NCD-RisC). 2017. Worldwide trends in body-mass index, underweight, overweight, and obesity from 1975 to 2016: a pooled analysis of 2416 population-based measurement studies in 128.9 million children, adolescents, and adults. Lancet 390:2627-2642.

NICE. 2014. Lipid modification: cardiovascular risk assessment and the modification of blood lipids for the primary and secondary prevention of cardiovascular disease (NICE guideline). National Institute for Health and Care Excellence. URL: https://www.nice.org.uk/guidance/cg181.

Ouzzani M, Hammady H, Fedorowicz Z, and Elmagarmid A. 2016. Rayyan-a web and mobile app for systematic reviews. Syst Rev 5:210. 
450 Ponte-Negretti Cl, Isea-Pérez J, Lanas F, Medina J, Gómez-Mancebo J, Morales E, Acevedo M, Pirskorz

451

452

453

454

455

456

457

458

459

460

461

462

463

464

465

466

467

468

469

470

471

472

473

474

475

476

477
D, Machado L, Lozada A, Bryce A, Lorenzatti A, Carrera C, López-Jaramillo P, Pinto X, and WyssQuintana FS. 2017. Atherogenic dyslipidemia in Latin America: prevalence, causes and treatment. Consensus. Revista mexicana de cardiología 28:57-85.

Ravnskov U, Diamond DM, Hama R, Hamazaki T, Hammarskjold B, Hynes N, Kendrick M, Langsjoen PH, Malhotra A, Mascitelli L, McCully KS, Ogushi Y, Okuyama H, Rosch PJ, Schersten T, Sultan S, and Sundberg R. 2016. Lack of an association or an inverse association between low-densitylipoprotein cholesterol and mortality in the elderly: a systematic review. BMJ open 6:e010401.

Schwingshackl L, Bogensberger B, Bencic A, Knuppel S, Boeing H, and Hoffmann G. 2018. Effects of oils and solid fats on blood lipids: a systematic review and network meta-analysis. J Lipid Res 59:17711782.

Secretaria de Salud. 2013. Guía de Tratamiento Farmacológico de Dislipidemias para el primer nivel de atención. Revista mexicana de cardiología 24:103-129.

Sistema General de Seguridad Social en Salud - Colombia. 2014. Guía de práctica clínica para la prevención, detección temprana, diagnóstico, tratamiento y seguimiento de las dislipidemias en la $\begin{array}{lllll}\text { población mayor } & 18 & \text { años. }\end{array}$ https://www.minsalud.gov.co/sites/rid/Lists/BibliotecaDigital/RIDE/INEC/IETS/GPC-Dislipidemicompleta.pdf.

Sociedad Argentina de Cardiologia. 2018. Uso apropiado de las estatinas en la Argentina Documento de posición. URL: https://www.sac.org.ar/wp-content/uploads/2018/06/documento-de-posicionconsenso-de-estatinas-2018.pdf.

Sociedad Uruguaya de Aterosclerosis. Segundo Consenso Uruguayo sobre Dislipidemias. URL: http://www.suc.org.uy/pdf/Consenso\%20Disli.pdf.

Sorlie PD, and Garcia-Palmieri MR. 1990. Educational status and coronary heart disease in Puerto Rico: the Puerto Rico Heart Health Program. Int J Epidemiol 19:59-65.

Werle MH, Moriguchi E, Fuchs SC, Bruscato NM, de Carli W, and Fuchs FD. 2011. Risk factors for cardiovascular disease in the very elderly: results of a cohort study in a city in southern Brazil. Eur J Cardiovasc Prev Rehabil 18:369-377. 
478 Yi SW, Shin DH, Kim H, Yi JJ, and Ohrr H. 2018. Total cholesterol and stroke mortality in middle-aged and 479 elderly adults: A prospective cohort study. Atherosclerosis 270:211-217.

480 Yusuf S, Bosch J, Dagenais G, Zhu J, Xavier D, Liu L, Pais P, Lopez-Jaramillo P, Leiter LA, Dans A, 481 Avezum A, Piegas LS, Parkhomenko A, Keltai K, Keltai M, Sliwa K, Peters RJ, Held C, Chazova I, 482 Yusoff K, Lewis BS, Jansky P, Khunti K, Toff WD, Reid CM, Varigos J, Sanchez-Vallejo G, McKelvie R, Pogue J, Jung H, Gao P, Diaz R, and Lonn E. 2016. Cholesterol Lowering in Intermediate-Risk Persons without Cardiovascular Disease. N Engl J Med 374:2021-2031. 
Figure 1

Flow-chart of the selection process. 


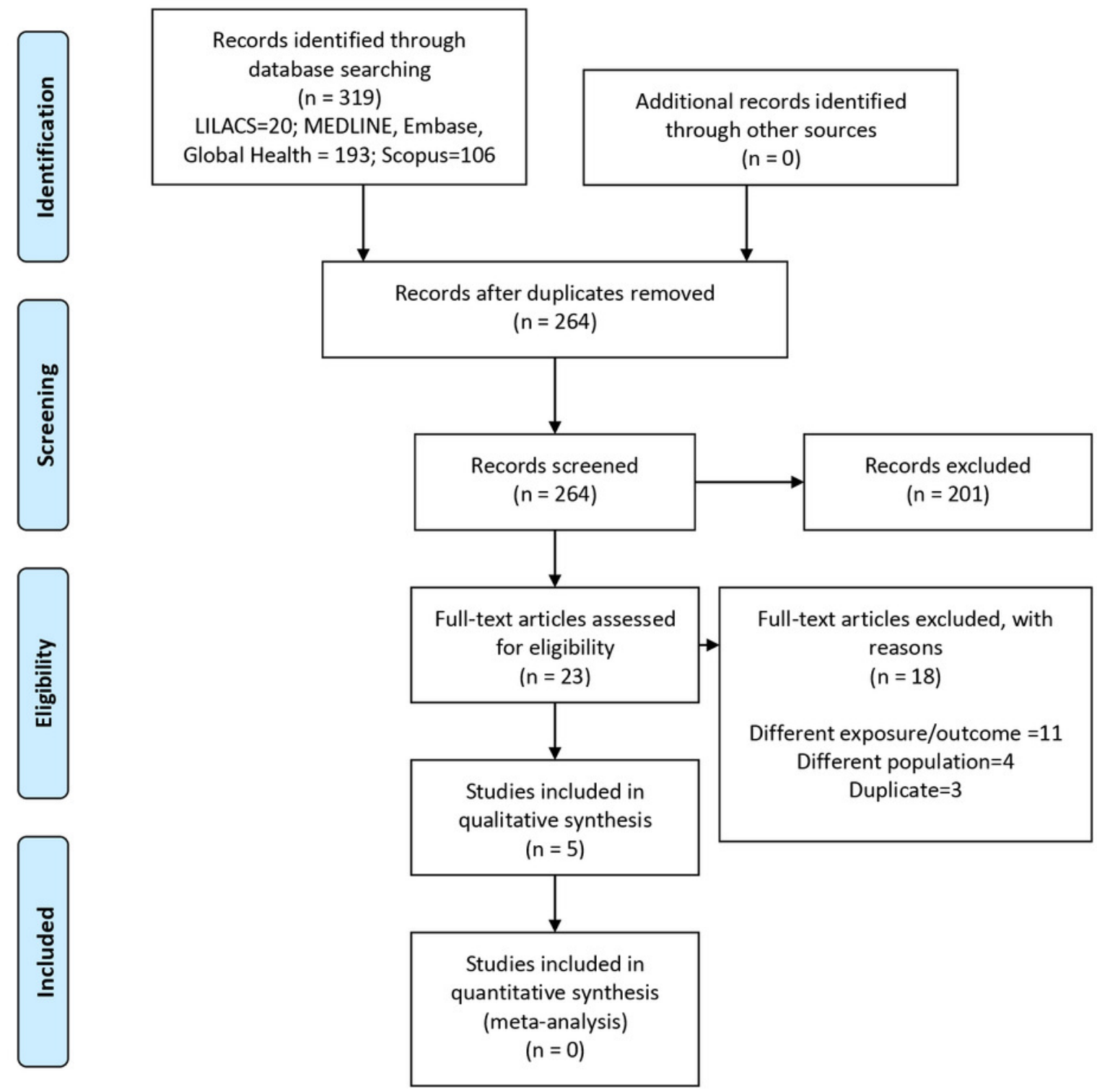


Figure 2

Call to action for Latin America in research and policy. 


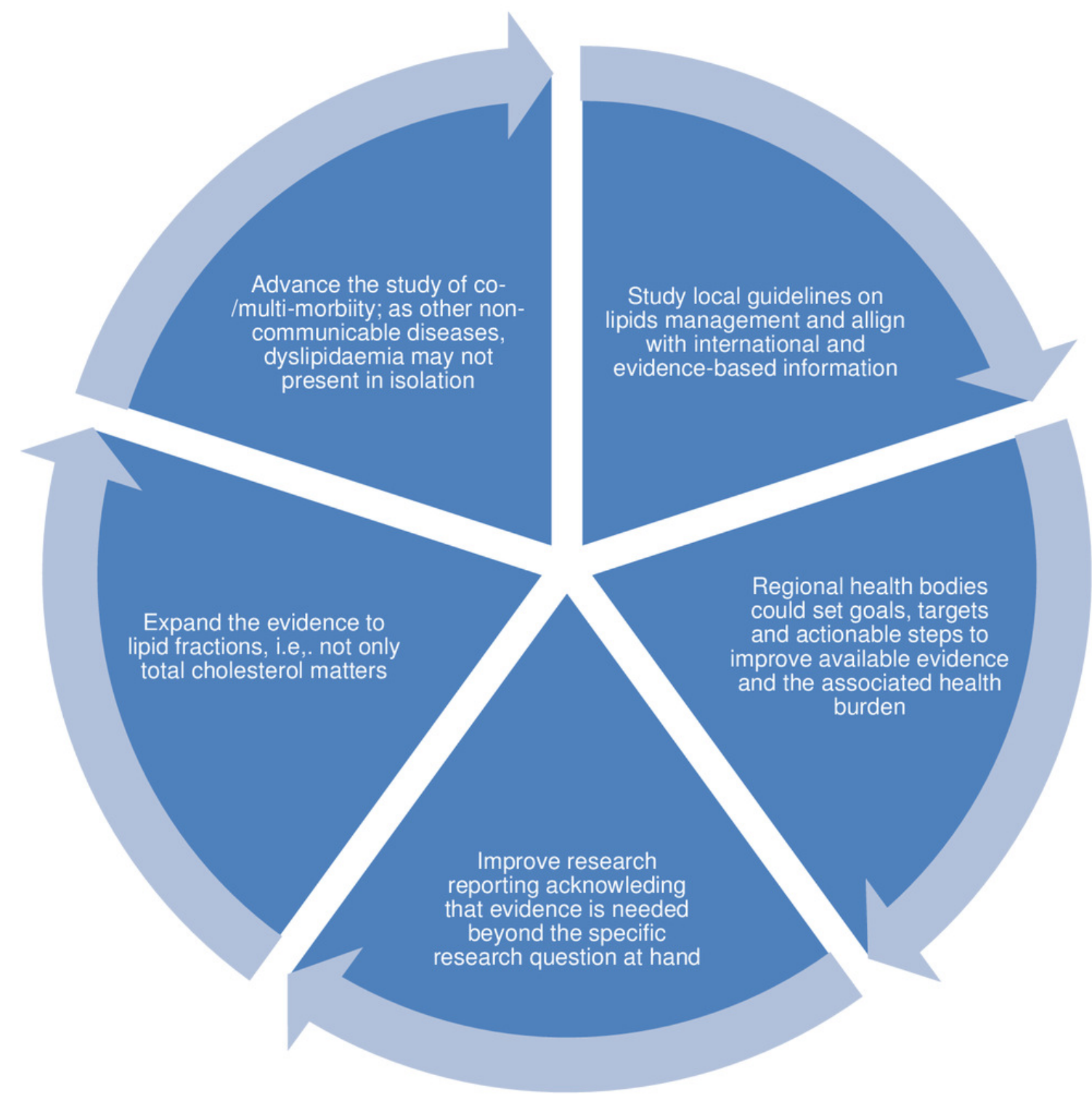




\section{Table 1 (on next page)}

Characteristics of the selected reports. 
Table 1. Characteristics of the selected reports.

\begin{tabular}{|c|c|c|c|c|c|c|c|c|c|c|c|c|}
\hline Author & $\begin{array}{l}\stackrel{Z}{L} \\
\stackrel{2}{J} \\
0\end{array}$ & 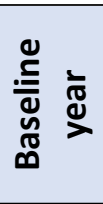 & 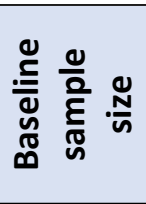 & 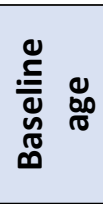 & $\begin{array}{l}\text { Baseline \% } \\
\text { men }\end{array}$ & 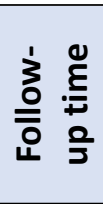 & $\begin{array}{c}\text { Body } \\
\text { mass } \\
\text { index } \\
\text { (mean) }\end{array}$ & Smoker & $\begin{array}{l}\text { Systolic } \\
\text { blood } \\
\text { pressure } \\
\text { (mean) }\end{array}$ & $\begin{array}{c}\text { Glucos } \\
\text { e } \\
\text { (mean) }\end{array}$ & Hypertension & Diabetes \\
\hline $\begin{array}{l}\text { Lazo-Porras(Lazo-Porras et al. } \\
\qquad 2016 \text { ) }\end{array}$ & 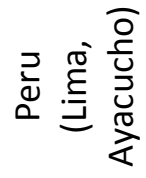 & 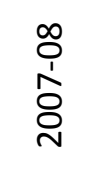 & $\begin{array}{l}\infty \\
\infty \\
\sigma\end{array}$ & $\stackrel{\infty}{\stackrel{\Xi}{\sim}}$ & 47 & 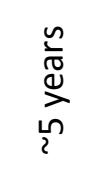 & $33.3 \% *$ & $3.3 \%$ & NA & NA & NA & NA \\
\hline Werle(Werle et al. 2011) & 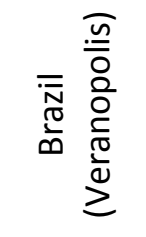 & ڤ̆ & $\stackrel{n}{\sigma}$ & म $\begin{array}{l}\bar{m} \\
\stackrel{n}{\ddot{n}}\end{array}$ & 36 & $\begin{array}{l}\frac{n}{\pi} \\
\stackrel{2}{2} \\
\frac{-1}{2}\end{array}$ & 26.7 & $6.7 \%$ & 168 & 5.4 & $93 \%$ & $17.6 \%$ \\
\hline $\begin{array}{l}\text { Garcia-Palmieri(Garcia- } \\
\text { Palmieri et al. 1981) }\end{array}$ & 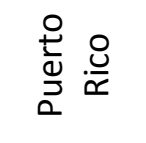 & ֻू & 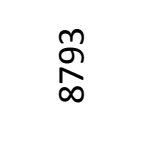 & $\begin{array}{l}\text { ठั } \\
\text { ஸें }\end{array}$ & 100 & 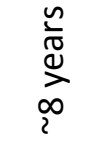 & NA & $\begin{array}{c}7.6 \\
¥\end{array}$ & 133 & 5.4 & NA & NA \\
\hline Crespo(Crespo et al. 2002) & $\frac{\stackrel{O}{\frac{t}{\alpha}}}{\frac{O}{a}}$ & ஜூ & $\begin{array}{l}\stackrel{\varphi}{m} \\
\stackrel{n}{\sigma}\end{array}$ & $\begin{array}{l}\stackrel{9}{1} \\
\text { nn }\end{array}$ & 100 & $\begin{array}{l}\frac{n}{\sqrt{0}} \\
\stackrel{2}{2} \\
\frac{1}{2}\end{array}$ & $49.7 \% *$ & $34.2 \% \xi$ & NA & NA & $35.4 \%$ & NA \\
\hline $\begin{array}{l}\text { Garcia-Palmieri(Garcia- } \\
\text { Palmieri et al. 1988) }\end{array}$ & 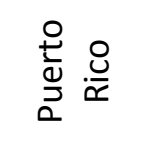 & ֻூ & $\underset{\substack{n \\
\infty}}{\stackrel{n}{\infty}}$ & 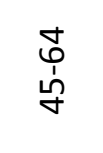 & 100 & 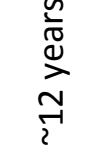 & NA & NA & NA & NA & NA & NA \\
\hline
\end{tabular}

2

3 *Overweight prevalence. $¥$ number smoker per day. $\xi$ non-smokers. SD=standard deviation. NA=not available. For Garcia-Palmieri's and Crespo’s

4 works the age is given as ranges. Glucose estimates are given as $\mathrm{mmol} / \mathrm{l}$. 
Crespo CJ, Palmieri MR, Perdomo RP, McGee DL, Smit E, Sempos CT, Lee IM, and Sorlie PD. 2002. The relationship of physical activity and body weight with all-cause mortality: results from the Puerto Rico Heart Health Program. Ann Epidemiol 12:543-552.

Garcia-Palmieri MR, Sorlie PD, Costas R, Jr., and Havlik RJ. 1981. An apparent inverse relationship between serum cholesterol and cancer mortality in Puerto Rico. Am J Epidemiol 114:29-40.

Garcia-Palmieri MR, Sorlie PD, Havlik RJ, Costas R, Jr., and Cruz-Vidal M. 1988. Urban-rural differences in 12 year coronary heart disease mortality: the Puerto Rico Heart Health Program. J Clin Epidemiol 41:285-292. cholesterol as a cardiovascular risk factor in rural, urban, and rural-urban migrants: PERU MIGRANT cohort study. Atherosclerosis 246:3643. 10.1016/j.atherosclerosis.2015.12.039

Werle MH, Moriguchi E, Fuchs SC, Bruscato NM, de Carli W, and Fuchs FD. 2011. Risk factors for cardiovascular disease in the very elderly: results of a cohort study in a city in southern Brazil. Eur J Cardiovasc Prev Rehabil 18:369-377. 10.1177/1741826710389405 
Table 2 (on next page)

Baseline lipid profile as in the summarised reports 
Table 2. Baseline lipid profile as in the summarised reports.

\begin{tabular}{|c|c|c|c|c|c|c|c|c|c|c|c|c|c|c|c|c|}
\hline \multirow[b]{2}{*}{ 高 } & \multicolumn{2}{|c|}{$\begin{array}{l}\text { Baseline Total } \\
\text { Cholesterol } \\
\text { (mg/dl) }\end{array}$} & \multirow{2}{*}{$\begin{array}{c}\text { If } \\
\text { prevalence, } \\
\text { what was } \\
\text { the } \\
\text { definition? }\end{array}$} & \multicolumn{2}{|c|}{$\begin{array}{c}\text { Baseline HDL } \\
\text { (mg/dl) }\end{array}$} & \multirow[b]{2}{*}{$\begin{array}{c}\text { If } \\
\text { prevalence, } \\
\text { what was } \\
\text { the } \\
\text { definition? }\end{array}$} & \multicolumn{2}{|c|}{$\begin{array}{l}\text { Baseline LDL } \\
\text { (mg/dl) }\end{array}$} & \multirow[b]{2}{*}{$\begin{array}{c}\text { If } \\
\text { prevalence, } \\
\text { what was } \\
\text { the } \\
\text { definition? }\end{array}$} & \multicolumn{2}{|c|}{$\begin{array}{c}\text { Baseline } \\
\text { Triglycerides } \\
\text { (mg/dl) }\end{array}$} & \multirow[b]{2}{*}{$\begin{array}{c}\text { If } \\
\text { prevalence, } \\
\text { what was } \\
\text { the } \\
\text { definition? }\end{array}$} & \multicolumn{2}{|c|}{$\begin{array}{l}\text { Baseline } \\
\text { Other } \\
\text { (specify) }\end{array}$} & \multirow[b]{2}{*}{ 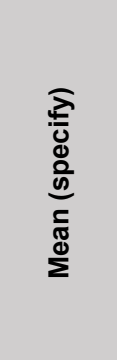 } & \multirow[b]{2}{*}{$\begin{array}{c}\text { If prevalence, } \\
\text { what was the } \\
\text { definition? }\end{array}$} \\
\hline & $\begin{array}{l}\text { Mean } \\
\text { (SD) }\end{array}$ & 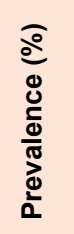 & & $\begin{array}{l}\text { Mean } \\
\text { (SD) }\end{array}$ & 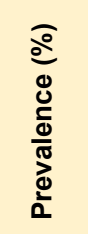 & & $\begin{array}{l}\text { Mean } \\
\text { (SD) }\end{array}$ & 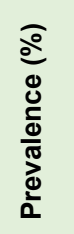 & & $\begin{array}{l}\text { Mean } \\
\text { (SD) }\end{array}$ & 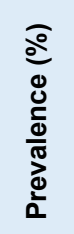 & & $\begin{array}{l}\text { Mean } \\
\text { (SD) }\end{array}$ & 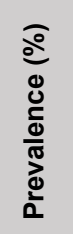 & & \\
\hline \multirow{5}{*}{ 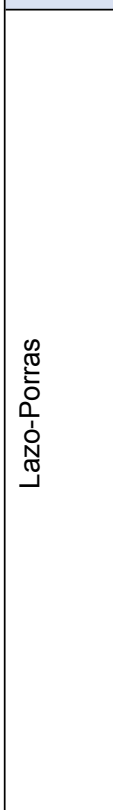 } & & & & & 56.5 & $\begin{array}{c}\text { Low HDL- } \\
\text { cholesterol } \\
\text { (HDL- } \\
\text { cholesterol < } \\
40 \text { in men } \\
\text { and }<50 \text { in } \\
\text { women) }\end{array}$ & & 3.0 & $\begin{array}{l}\text { LDL- } \\
\text { cholesterol } \\
>160\end{array}$ & & 4.0 & $\begin{array}{l}\text { Triglycerides } \\
\geq 200\end{array}$ & & 3.0 & & $\begin{array}{l}\text { LDL-cholesterol } \\
>160, \\
\text { triglycerides } \\
\geq 200 \text { \& low } \\
\text { HDL-cholesterol }\end{array}$ \\
\hline & & & & & 36.5 & $\begin{array}{l}\text { Isolated low } \\
\text { HDL- } \\
\text { cholesterol }\end{array}$ & & 2.0 & $\begin{array}{c}\text { LDL- } \\
\text { cholesterol } \\
>160 \& \\
\text { triglycerides } \\
\geq 200\end{array}$ & & & & & & & \\
\hline & & & & & 91.6 & $\begin{array}{c}\text { High non- } \\
\text { HDL- } \\
\text { cholesterol }\end{array}$ & & & & & & & & & & \\
\hline & & & & & 15.0 & $\begin{array}{l}\text { Low HDL- } \\
\text { cholesterol } \\
\text { and } \\
\text { triglycerides } \\
\geq 200\end{array}$ & & & & & & & & & & \\
\hline & & & & & 2.0 & $\begin{array}{l}\text { Low HDL- } \\
\text { cholesterol } \\
\& \text { LDL- } \\
\text { cholesterol } \\
>160\end{array}$ & & & & & & & & & & \\
\hline \multirow{2}{*}{$\frac{0}{\frac{0}{\omega}}$} & $\begin{array}{l}211.6 \\
\text { (SD: } \\
47.4) \\
\end{array}$ & & & $\begin{array}{l}45.5 \\
\text { (SD: } \\
12.6) \\
\end{array}$ & & & $\begin{array}{l}139.1 \\
\text { (SD: } \\
42.5) \\
\end{array}$ & & & $\begin{array}{l}137.2 \\
(\mathrm{SD}: \\
65.6)\end{array}$ & & & $\begin{array}{l}165.4 \\
\text { (SD: } \\
33.7)\end{array}$ & & $\begin{array}{l}\text { ApoA-I } \\
\text { (mg/dL) }\end{array}$ & \\
\hline & & & & & & & & & & & & & $\begin{array}{l}87.5 \\
\text { (SD: } \\
21.0)\end{array}$ & & $\begin{array}{c}\text { ApoB- } \\
100 \\
(\mathrm{mg} / \mathrm{dL})\end{array}$ & \\
\hline
\end{tabular}




\section{PeerJ}

Manuscript to be reviewed

\begin{tabular}{|l|l|l|l|l|l|l|l|l|l|l|l|l|l|l|}
\hline \\
\hline
\end{tabular}




\section{Table 3(on next page)}

Risk estimates of lipid biomarkers on mortality as in the summarised reports 
Table 3. Risk estimates of lipid biomarkers on mortality as in the summarised reports.

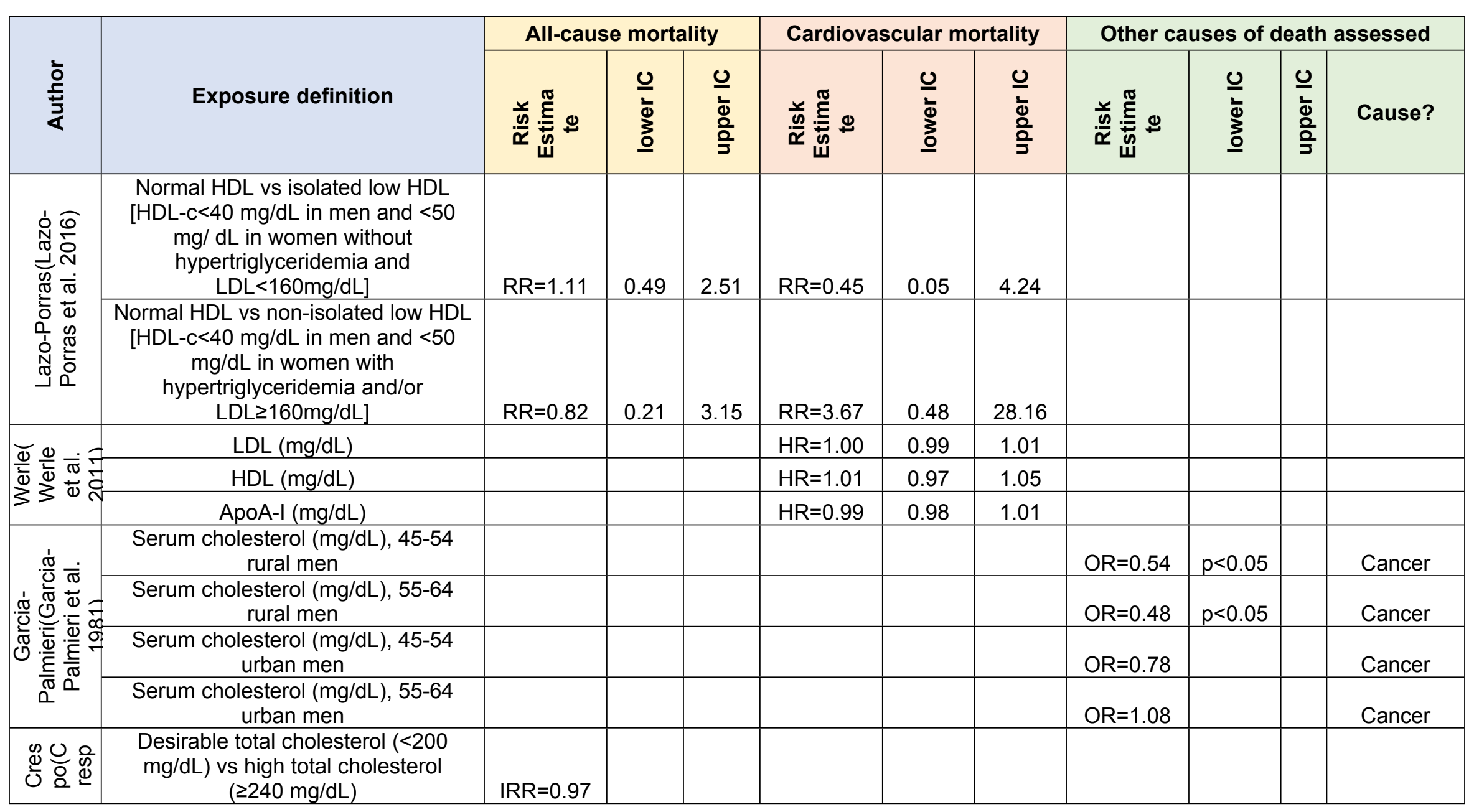




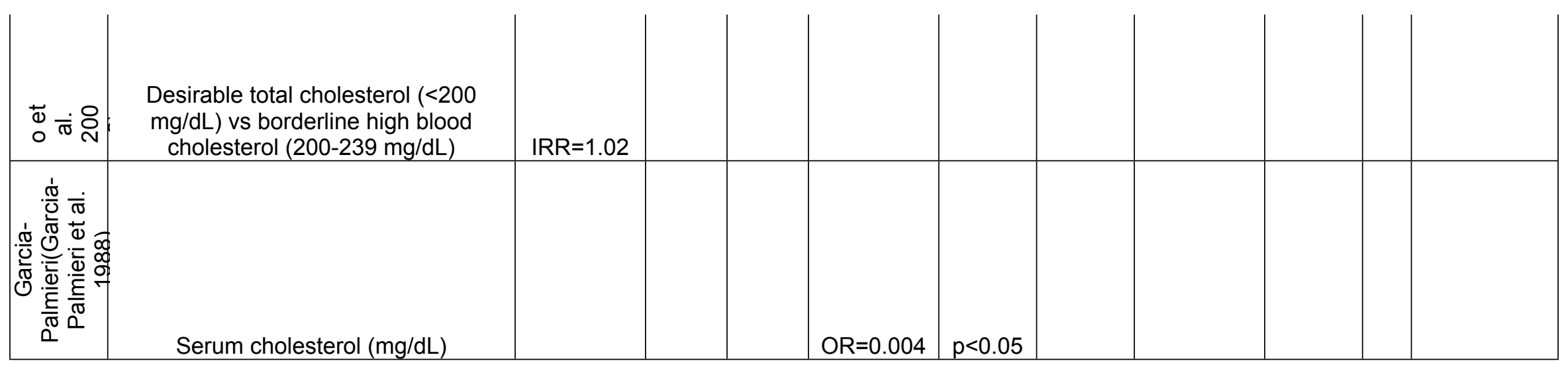

Garcia-Palmieri, 1981 - Reported multiple regression coefficients ["The logistic function was used to model the relationship between cancer mortality and serum cholesterol"], so that the OR herein reported corresponds to the exponential function of the coefficients in the manuscript. Crespo, 2002 - The authors did not provide risk estimates; the IRR herein reported corresponds to the relation between crude death rates among people with high cholesterol (crude death rate $=16.3 \%$ ), borderline high blood cholesterol (crude death rate $=15.5 \%$ ) and desirable cholesterol (crude death rate $=15.8 \%$ ). For example, 15.8/16.3 $\sim 0.97$. Where available, the risk estimates herein summarized correspond to the adjusted models reported in the original reports.

Crespo CJ, Palmieri MR, Perdomo RP, McGee DL, Smit E, Sempos CT, Lee IM, and Sorlie PD. 2002. The relationship of physical activity and body weight with all-cause mortality: results from the Puerto Rico Heart Health Program. Ann Epidemiol 12:543-552.

Garcia-Palmieri MR, Sorlie PD, Costas R, Jr., and Havlik RJ. 1981. An apparent inverse relationship between serum cholesterol and cancer mortality in Puerto Rico. Am J Epidemiol 114:29-40. mortality: the Puerto Rico Heart Health Program. J Clin Epidemiol 41:285-292. 
Lazo-Porras M, Bernabe-Ortiz A, Malaga G, Gilman RH, Acuna-Villaorduna A, Cardenas-Montero D, Smeeth L, and Miranda JJ. 2016. Low HDL cholesterol as a cardiovascular risk factor in rural, urban, and rural-urban migrants: PERU MIGRANT cohort study. Atherosclerosis 246:3643. 10.1016/j.atherosclerosis.2015.12.039

Werle MH, Moriguchi E, Fuchs SC, Bruscato NM, de Carli W, and Fuchs FD. 2011. Risk factors for cardiovascular disease in the very elderly: 
Table 4 (on next page)

Risk of bias assessment 
Table 4. Risk of bias assessment.

2

\begin{tabular}{|c|c|c|c|}
\cline { 2 - 4 } \multicolumn{1}{c|}{} & selection & Comparability & Outcome \\
\hline $\begin{array}{c}\text { Lazo-Porras(Lazo- } \\
\text { Porras et al. 2016) }\end{array}$ & $\star \star \star \star$ & $\star \star$ & $\star \star \star$ \\
\hline $\begin{array}{c}\text { Werle(Werle et al. } \\
\text { 2011) }\end{array}$ & $\star \star \star$ & $\star \star$ & $\star \star \star$ \\
\hline $\begin{array}{c}\text { Garcia- } \\
\text { Palmieri(Garcia- } \\
\text { Palmieri et al. 1981) }\end{array}$ & $\star \star \star$ & $\star$ & $\star \star$ \\
\hline $\begin{array}{c}\text { Crespo(Crespo et al. } \\
\text { 2002) }\end{array}$ & $\star \star \star \star$ & $\star \star$ & $\star \star \star$ \\
\hline $\begin{array}{c}\text { Garcia- } \\
\text { Palmieri(Garcia- } \\
\text { Palmieri et al. 1988) }\end{array}$ & $\star \star \star$ & & \\
\hline
\end{tabular}

3

4 The more stars the less risk of bias the study has

5

6 Crespo CJ, Palmieri MR, Perdomo RP, McGee DL, Smit E, Sempos CT, Lee IM, and Sorlie PD. 2002. The relationship of physical activity and body weight with all-cause mortality: results from the Puerto Rico Heart Health Program. Ann Epidemiol 12:543-552.

Garcia-Palmieri MR, Sorlie PD, Costas R, Jr., and Havlik RJ. 1981. An apparent inverse relationship between serum cholesterol and cancer mortality in Puerto Rico. Am J Epidemiol 114:29-40.

Garcia-Palmieri MR, Sorlie PD, Havlik RJ, Costas R, Jr., and Cruz-Vidal M. 1988. Urban-rural differences in 12 year coronary heart disease mortality: the Puerto Rico Heart Health Program. J Clin Epidemiol 41:285-292.

Lazo-Porras M, Bernabe-Ortiz A, Malaga G, Gilman RH, Acuna-Villaorduna A, Cardenas-Montero D, Smeeth L, and Miranda JJ. 2016. Low HDL cholesterol as a cardiovascular risk factor in rural, urban, and rural-urban migrants: PERU MIGRANT cohort study. Atherosclerosis 246:36-43. 10.1016/j.atherosclerosis.2015.12.039 
18 Werle MH, Moriguchi E, Fuchs SC, Bruscato NM, de Carli W, and Fuchs FD. 2011. Risk factors for 